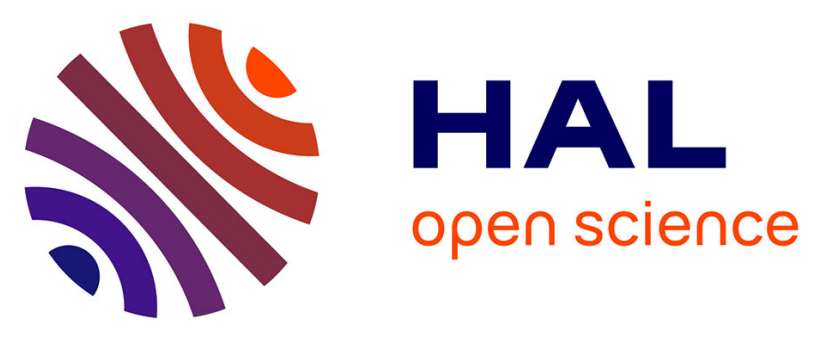

\title{
Chemical Engineering Journal Photon energy conversion and management in SrAl12O19: Mn2+, Gd3+ for rewritable optical information storage
}

Xiaohui Lin, Kaiyuan Deng, Haoyi Wu, Bingsheng Du, Bruno Viana, Yang Li, Yihua $\mathrm{Hu}$

\section{To cite this version:}

Xiaohui Lin, Kaiyuan Deng, Haoyi Wu, Bingsheng Du, Bruno Viana, et al.. Chemical Engineering Journal Photon energy conversion and management in SrAl12O19: $\mathrm{Mn} 2+, \mathrm{Gd} 3+$ for rewritable optical information storage. Chemical Engineering Journal, 2021, 420, Part 1, pp.129844. 10.1016/j.cej.2021.129844 . hal-03447653

\section{HAL Id: hal-03447653 \\ https://hal.science/hal-03447653}

Submitted on 24 Nov 2021

HAL is a multi-disciplinary open access archive for the deposit and dissemination of scientific research documents, whether they are published or not. The documents may come from teaching and research institutions in France or abroad, or from public or private research centers.
L'archive ouverte pluridisciplinaire HAL, est destinée au dépôt et à la diffusion de documents scientifiques de niveau recherche, publiés ou non, émanant des établissements d'enseignement et de recherche français ou étrangers, des laboratoires publics ou privés. 


\section{Chemical Engineering Journal}

\section{Photon energy conversion and management in SrAl12019: Mn2+, Gd3+ for rewritable optical information storage \\ --Manuscript Draft--}

\begin{tabular}{|l|l|}
\hline Manuscript Number: & CEJ-D-21-02606 \\
\hline Article Type: & Research Paper \\
\hline Section/Category: & Novel Materials for Energy and Advanced Applications \\
\hline Keywords: & $\begin{array}{l}\text { Optical information storage; SrAl12O19: Mn2+, Gd3+; Optical stimulated } \\
\text { luminescence }\end{array}$ \\
\hline Abstract: & $\begin{array}{l}\text { In the current big data era, the state-of-the-art optical data storage has become a front- } \\
\text { runner in the competing data storage technologies. In this work, we proposed an } \\
\text { information storage prototype using optical stimulated luminescent phosphor of SrAl } \\
12 \text { O } 19: \text { Mn } 2+, \text { Gd } 3+, \text { which converts the photon into trapped electrons and } \\
\text { partial releases them in a form of luminescence when it is irradiated by infrared } \\
\text { irradiation, rendering an optical information storaging ability. The information storage } \\
\text { can be realized in both graphical and digital format. In this way, graphical patterns can } \\
\text { be stored and rejuvenated by infrared irradiation, and a set of digital data is recorded } \\
\text { step by step by a home-make decoding system, completing an optical data reading } \\
\text { process. This work provides a practical example for future application of writing-storing- } \\
\text { readout-erasing-rewriting integrated optical information storage. }\end{array}$ \\
\hline
\end{tabular}




\section{Research highlights}

- Optical stimulated luminescence is observed from $\mathrm{SrAl}_{12} \mathrm{O}_{19}: \mathrm{Mn}^{2+}, \mathrm{Gd}^{3+}$.

- The detrapping of electrons is operable by controlling the IR laser.

- An optical information storage that integrate a writing-storing-readout-erasingrewriting is realized. 


\title{
Photon energy conversion and management in $\mathrm{SrAl}_{12} \mathrm{O}_{19}: \mathrm{Mn}^{2+}$, $\mathrm{Gd}^{3+}$ for rewritable optical information storage
}

\author{
Xiaohui Lin ${ }^{a}$, Kaiyuan Deng ${ }^{a}$, Haoyi Wu ${ }^{a}$, Bingsheng Du ${ }^{b}$,Bruno Viana ${ }^{c}$, Yang Li ${ }^{a} *$, Yihua Hu ${ }^{a, *}$ \\ a School of Physics and Optoelectronic Engineering, Guangdong University of Technology, Guangzhou 510006, China \\ ${ }^{b}$ Key Laboratory of Optoelectronic Technology and System of Ministry of Education, College of Optoelectronic \\ Engineering, Chongqing University, Chongqing 400044, China. \\ ${ }^{\mathrm{c}}$ PSL Research University, Institut de Recherche de Chimie Paris, Chimie ParisTech, Paris 75005, France.
}

\begin{abstract}
In the current big data era, the state-of-the-art optical data storage has become a front-runner in the competing data storage technologies. In this work, we proposed an information storage prototype using optical stimulated luminescent phosphor of $\mathrm{SrAl}_{12} \mathrm{O}_{19}: \mathrm{Mn}^{2+}, \mathrm{Gd}^{3+}$, which converts the photon into trapped electrons and partial releases them in a form of luminescence when it is irradiated by infrared irradiation, rendering an optical information storaging ability. The information storage can be realized in both graphical and digital format. In this way, graphical patterns can be stored and rejuvenated by infrared irradiation, and a set of digital data is recorded step by step by a home-make decoding system, completing an optical data reading process. This work provides a practical example for future application of writing-storing-readout-erasing-rewriting integrated optical information storage.
\end{abstract}

Keywords: Optical information storage; $\mathrm{SrAl}_{12} \mathrm{O}_{19}: \mathrm{Mn}^{2+}, \mathrm{Gd}^{3+}$; Optical stimulated luminescence

*Corresponding authors

Emails: manofchina@outlook.com (H. Wu), lychris@sina.com (Y. Li), huyh@gdut.edu.cn (Y.Hu) 


\section{Introduction}

The application of photon is usually focused on their conversion to photovoltage that could produce electricity. Then materials for photovoltage need not only photon absorption but also charge carrier transportation. Some materials process an insufficient carriers transporting ability because of defects in crystal may not a candidate for photovoltage conversion, but could be a photon-trapped carriers converter, such as optical stimulated luminescence (OSL) and thermoluminescence (TL).[1-5] Both are the phenomenon where excited charge carriers are trapped by lattice defect and released to luminescent centers accompanied by photon emission. Based on the photon or thermal induced emission, both OSL and TL can realize information storage after patterning by means of carriers' liberation. As listed in Table 1, depending on the amount of trapped depth that reflects the liberation energy, the thermal energy obtained from heat at a mild temperature may be insufficient to activate the trapped carriers in some phosphors [1-9]. Then the pattern can be only rejuvenated when the material is heated to a high temperature. Such prototype is suitable to disposable or confidential communication but not for set-upping the interface connecting to patterns and computers or machine. Instead of thermal energy in TL, the liberation of trapped carriers in OSL is induced by photon energy, which is normally higher than the thermal ones and sufficient to activate carrier trapped in many lattice defects.[1,4] It renders OSL more feasible to rejuvenate the information patterns. Moreover, photons used to activate trapped carriers can be confined temporally and spatially, such as laser pulse, making them feasible to manage the trapped carriers by suitable operation.[7] Therefore, the research on OSL coupled with persistent luminescent phosphors (PLPs) will open a window for information storage since the materials have been widely used as indicators, whose behavior make them as some response signal of sensing, inducing the fluorescence quenching of afterglow fluorescent marker. In particular, 
carriers stored in defects PLPs releasable by near infrared (NIR) light excitation, enabling an information storaging and managing capability.

In recent decades, aluminate based PSPs have been demonstrated as one of the considerable host available to transition metal ions doping for various kinds of luminescent applications. Due to available deep traps, metal cations doped $\mathrm{SrAl}_{12} \mathrm{O}_{19}$ appears as possible OSL phosphor. Previously, $\mathrm{Fe}^{3+}$ and $\mathrm{Ce}^{3+}$ ions in $\mathrm{SrAl}_{12} \mathrm{O}_{19}$ demonstrated IR and ultraviolet emission respectively, as well as TL and OSL phenomena [11,12]. However, these emissions are not suitable for lighting with naked eye and furthermore detectors for IR and ultraviolet remain costly. Thus OSL with visible light is more desirable for information storage. The $\mathrm{Eu}^{2+}$ ion doped $\mathrm{SrAl}_{2} \mathrm{O}_{4}$ and $\mathrm{CaAl}_{2} \mathrm{O}_{4}$ are typical TL materials with visible light emission and persistent luminescence when codoped with $\mathrm{Dy}^{3+}$ and $\mathrm{Nd}^{3+}$ ions respectively [13,14]. These phenomena are induced with traps depth about $0.5 \sim 0.7 \mathrm{eV}$, for which trapped carriers can be thermally released at room temperature $[15,16,17]$. Yet, such traps depth is not advantageous to activate OSL phenomenon because most of the trapped carriers are bleached at room temperature. Therefore, the key for searching a suitable OSL material is finding out suitable traps with proper depth that could stably store charge carriers at room temperature.

Here, we demonstrate a green OSL observed from $\mathrm{Mn}^{2+}$ doped $\mathrm{SrAl}_{12} \mathrm{O}_{19}$ phosphor, whose trap depth is estimated to be $0.7 \sim 1.1 \mathrm{eV}$, enabling a carrier storage ability. By co-doping with $\mathrm{Gd}^{3+}$ ions, the density of the trapped carriers can be strengthened. After an initial excitation by ultraviolet (UV), carriers are excited to traps and then OSL is induced by IR laser excitation, which provide sufficient photon energy to release carriers from traps. A expected, the number of trapped carriers decreased with 
the increase of either time or excitation power, giving raise to the photon energy management. Thus it demonstrates the feasible to a writing-storing-readout-erasing-rewriting process in one set, which is advantageous towards optical data storage. The system with such strategy provides a new prototype for future optical information storage.

\section{Experimental Section}

\subsection{Materials and Preparation of $\mathrm{SrAl}_{12} \mathrm{O}_{19}: \mathrm{A} \% \mathrm{Mn}^{2+} \mathrm{B} \% \mathrm{Gd}^{3+}$ phosphors}

$\mathrm{SrCO}_{3}(99.95 \%), \mathrm{Al}_{2} \mathrm{O}_{3}(99.99 \%), \mathrm{MnO}_{2}(99.99 \%), \mathrm{Gd}_{2} \mathrm{O}_{3}(99.99 \%)$, and $\mathrm{H}_{3} \mathrm{BO}_{3}(99.99 \%)$ and methyl methacrylate were purchased from Macklin. $\mathrm{SrAl}_{12} \mathrm{O}_{19}$ : $\mathrm{A} \% \mathrm{Mn}^{2+} \mathrm{B} \% \mathrm{Gd}^{3+}$ phosphors were produced through solid state reactions. The initial calcination was performed at $800^{\circ} \mathrm{C}$ for $12 \mathrm{~h}$. The mixtures were then grounded in an agate mortar for $15 \mathrm{~min}$ and finally sintered at $1500{ }^{\circ} \mathrm{C}$ for $4 \mathrm{~h}$. Then, $\mathrm{SrAl}_{12} \mathrm{O}_{19}: \mathrm{A} \% \mathrm{Mn}^{2+} \mathrm{B} \% \mathrm{Gd}^{3+}$ phosphor were sintered under a reductive atmosphere $\left(20 \% \mathrm{H}_{2}+80 \%\right.$ $\mathrm{N}_{2}$ ). Fig. S1 shows $\mathrm{SEM}$ and EDS mapping of $\mathrm{SrAl}_{12} \mathrm{O}_{19}: 0.5 \% \mathrm{Mn}^{2+}, 5 \% \mathrm{Gd}^{3+}$.

\subsection{Characterization}

The phase identification of as-synthesized phosphors were characterized via X-ray diffractometer (Beijing, Puxi XD-2) using $\mathrm{Cu} \mathrm{K \alpha}$ irradiation $(\lambda=1.5405 \AA)$ at $36 \mathrm{kV}$ and $20 \mathrm{~mA}$ to confirm the presence of $\mathrm{SrAl}_{12} \mathrm{O}_{19}$ as the sole crystalline phase. Room-temperature photoluminescence (PL), PL excitation (PLE) spectra, afterglow spectra and decay curves were measured with a high-resolution spectrofluorometer (UK, Edinburgh Instruments, FLS980) equipped with a $500 \mathrm{~W}$ Xenon lamp as an excitation source, with a Hamamatsu R928P visible (VIS) photomultiplier $(250-850 \mathrm{~nm})$ as the 
detectors. Thermo-luminescence glow curves were measured with a SL08-L meter(Guangzhouradiation science and technology) by heating the irradiated phosphors from room temperature up to $350{ }^{\circ} \mathrm{C}$.

\subsection{Disc-like digital data storage prototype:}

The disc-like digital data storage prototype is fabricated with a rotating disc holder, a fixing IR laser and liner array CCD camera. The disc were covered by a photomask of specific information and irradiated for 10 min by UV light ( $254 \mathrm{~nm}$ ) and aging for 24 hours. After the removal of UV light and photomask, the desired information was recorded. In this process, $254 \mathrm{~nm}$ laser was used as the writein light source, while 980 laser was used as readout light source to access the information stored in trap in a rotation mode.

\section{Results and Discussion}

The data storage of OSL is illustrated in 3 basic steps, including writing, reading and erasing. As shown in Fig. 1, traps are created during a high temperature synthesizing process. A small number of charge carriers may exist in traps when the crystal is formed. After excited by ultra- violet light, electrons are excited from the ground state to the excited state of $\mathrm{Mn}^{2+}$, and most of them return to ground state accompanied by photon emission (PL). Some of the excited carriers are transferred to traps through the conduction bands -because of the small gap between the bottom of conduction band and the $\mathrm{d}$ levels of $\mathrm{Mn}^{2+}$ ions- or by tunneling. After this first filling process, the so-call "writing process" for data storage is completed. When traps are sufficiently deep stored carriers stand stability in such deep traps. In OSL phenomenon, NIR laser excitation could release the carriers from these traps leading to 
a readable pattern and generate green emission in $\mathrm{SrAl}_{12} \mathrm{O}_{19}: 0.5 \% \mathrm{Mn}^{2+}, 5 \% \mathrm{Gd}^{3+}$ phosphor. After switching-off the NIR laser, persistent luminescence occurs for long time [10, 18]. During this procedure, the recorded photons also serve as OSL response for data reading. The traps could be bleached by returning all electrons to luminescence in the case of sufficient excitation power or excitation time, showing a data erasing ability. Then the phosphor could be rewritten, going to another storage cycle.

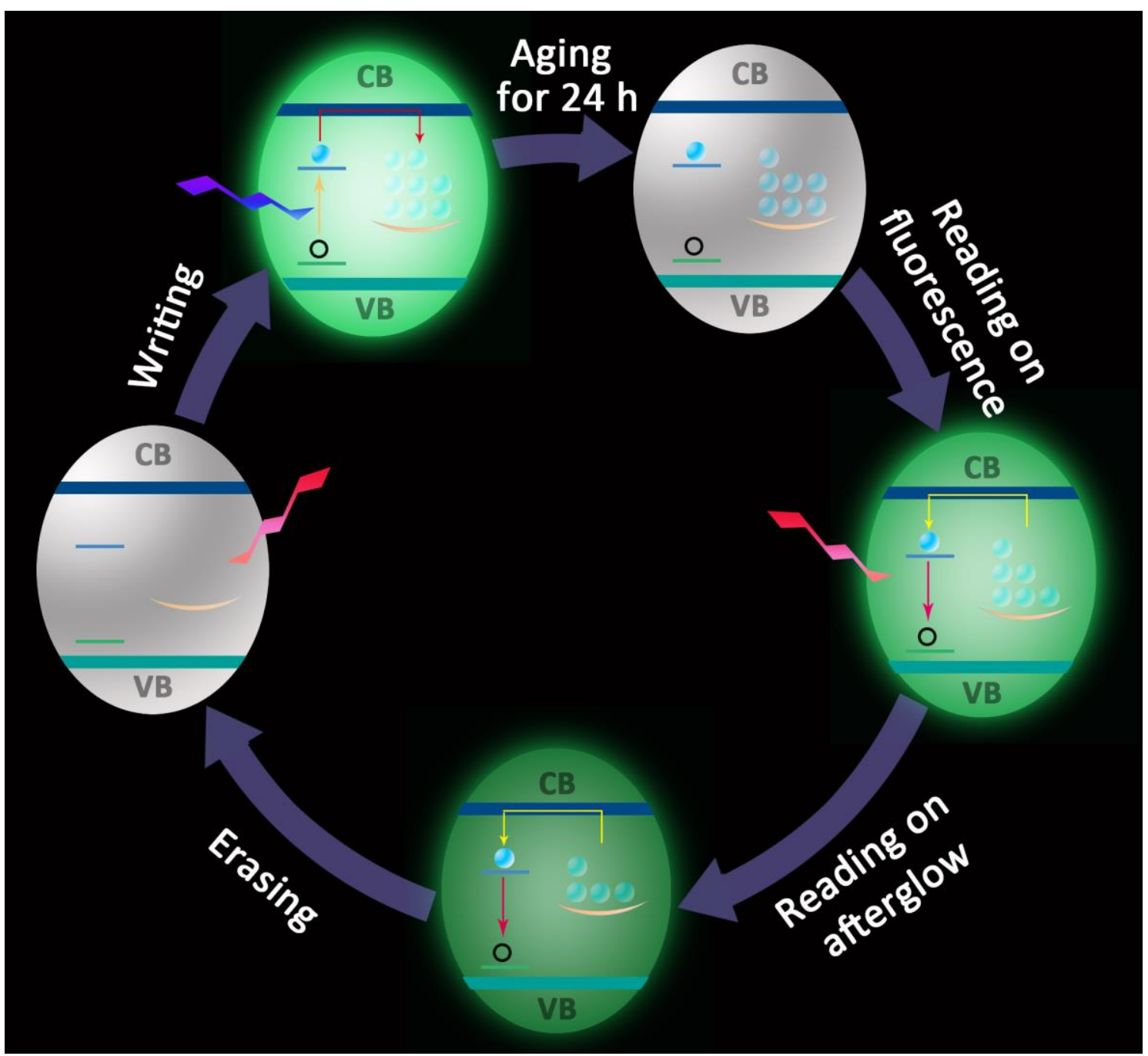

Fig. 1 Diagrammatic rewritable information storage based on OSL. 

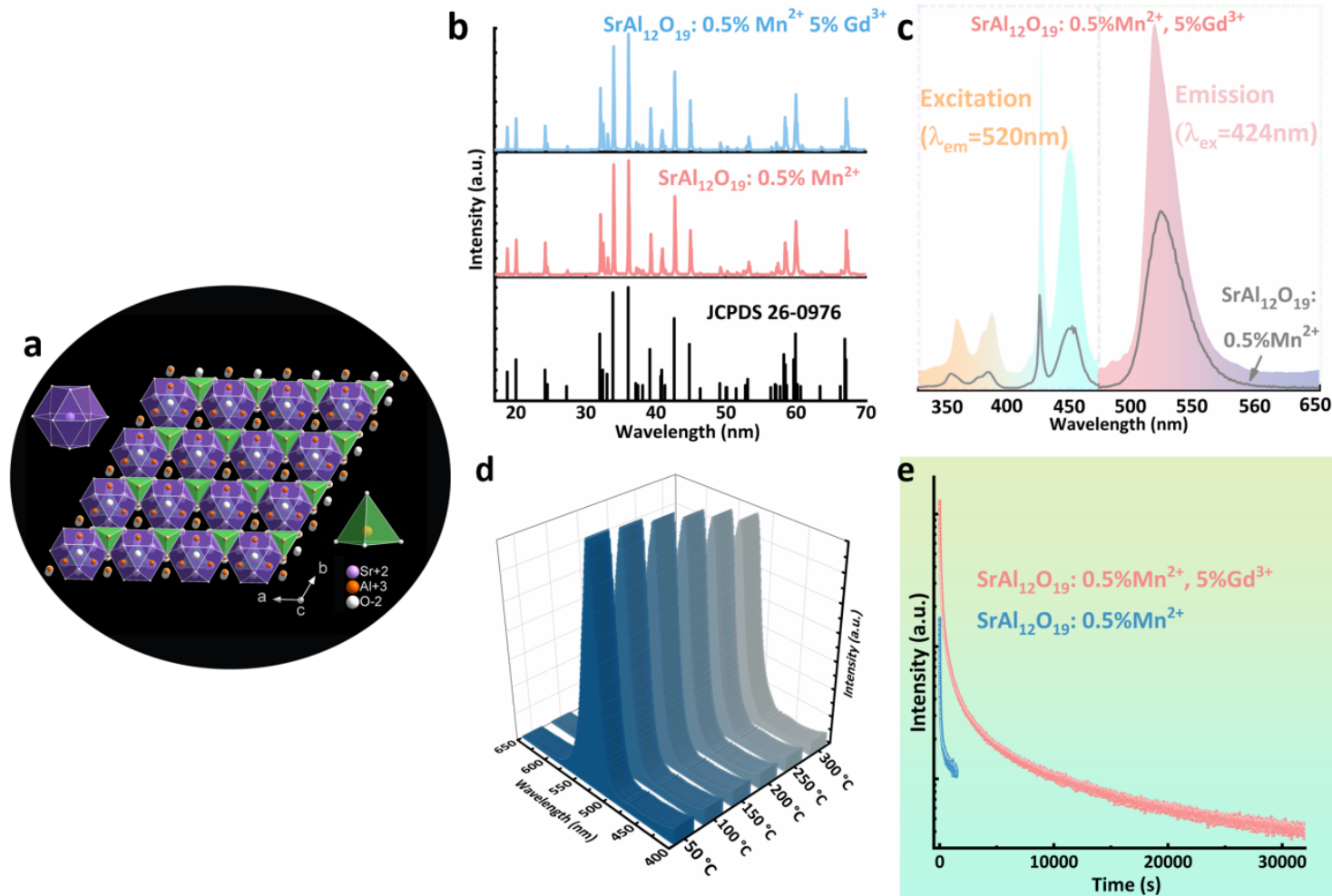

Fig. 2 (a) Schematic diagram of $\mathrm{SrAl}_{12} \mathrm{O}_{19}$ structure and coordination environments of the $\mathrm{Al}^{3+}$ cations. (b) XRD patterns for $\mathrm{SrAl}_{12} \mathrm{O}_{19}: 0.5 \% \mathrm{Mn}^{2+}, 5 \% \mathrm{Gd}^{3+}$ and $\mathrm{SrAl}_{12} \mathrm{O}_{19}: 0.5 \% \mathrm{Mn}^{2+}$ phosphors. (c) Photoluminescence spectrum and photoluminescence excitation spectrum of $\mathrm{SrAl}_{12} \mathrm{O}_{19}$ : $0.5 \% \mathrm{Mn}^{2+}, 5 \% \mathrm{Gd}^{3+}$ and $\mathrm{SrAl}_{12} \mathrm{O}_{19}$ : $0.5 \% \mathrm{Mn}^{2+}$ phosphors; (d) Variable temperature PL emission spectra of $\mathrm{SrAl}_{12} \mathrm{O}_{19}: 0.5 \% \mathrm{Mn}^{2+}, 5 \% \mathrm{Gd}^{3+}$ phosphor under $424 \mathrm{~nm}$ excitation wavelength. (e) Afterglow intensity monitored at $520 \mathrm{~nm}$ of $\mathrm{Mn}^{2+}$ in $\mathrm{SrAl}_{12} \mathrm{O}_{19}$ : $0.5 \% \mathrm{Mn}^{2+}, 5 \% \mathrm{Gd}^{3+}$ phosphor after being pre-irradiated by $30 \mathrm{~W} \mathrm{UV}$ lamp for $10 \mathrm{~min}$.

The $\mathrm{SrAl}_{12} \mathrm{O}_{19}: 0.5 \% \mathrm{Mn}^{2+}$ and $\mathrm{SrAl}_{12} \mathrm{O}_{19}: 0.5 \% \mathrm{Mn}^{2+}, 5 \% \mathrm{Gd}^{3+}$ phosphors were employed to realize the re-writable OSL prototype. As confirmed by XRD shown in Fig. 2b, pure $\mathrm{SrAl}_{12} \mathrm{O}_{19}$ phase is observed according to the JCPDS standard card (No. 26-0976) [19]. The structure of the phosphor has a hexagonal magnetoplumbite structure with $\mathrm{P} 63 / \mathrm{mmc}$ space group (with lattice parameters $\mathrm{a}=0.5585 \mathrm{~nm}, \mathrm{~b}=0.5585 \mathrm{~nm}$, and $\mathrm{c}=2.207 \mathrm{~nm}$ ) (Fig. 2a) $[20,21]$. The potential lattice site for $\mathrm{Mn}^{2+}$ substitution is the $\mathrm{Al}^{3+}$ ions which occupy five different lattice sites, in which four sites have $\mathrm{O}^{2-}$ ligands, constituting $\left[\mathrm{AlO}_{4}\right]$ tetrahedral structure. As expected with such low content, the structure change induced by the doping of $\mathrm{Mn}^{2+}$ and $\mathrm{Gd}^{3+}$ is not detectable [22]. The PL spectra of $\operatorname{SrAl}_{12} \mathrm{O}_{19}$ : 
$0.5 \% \mathrm{Mn}^{2+}$ and $\mathrm{SrAl}_{12} \mathrm{O}_{19}: 0.5 \% \mathrm{Mn}^{2+}, 5 \% \mathrm{Gd}^{3+}$ excited at $424 \mathrm{~nm}$ irradiation are shown in Fig. $2 \mathrm{c}$. In the $\mathrm{SrAl}_{12} \mathrm{O}_{19}, \mathrm{Mn}^{2+}$ coordinated with the tetrahedron produces a single band green emission centered at $520 \mathrm{~nm}$ which is attributed to d-d transition $\left({ }^{4} \mathrm{~T}_{1} \rightarrow{ }^{6} \mathrm{~A}_{1}\right)$ of $\mathrm{Mn}^{2+}$. A codoping strategy of $\mathrm{Gd}^{3+}$ is proposed to enhance the afterglow intensity, since $\mathrm{Gd}^{3+}$ has been proven its ability to control the trap distribution and to improve the persistent duration. The codoping of $\mathrm{Gd}^{3+}$ ion does not affect the other spectroscopic configuration of $\mathrm{Mn}^{2+}$ [23]. The PLE spectra showed five distinct peaks centered at 358, 382, 424 and 450 (Fig. 2c) which are assigned to the transitions of $\mathrm{Mn}^{2+}$ from ground levels ${ }^{6} \mathrm{~A}_{1}\left({ }^{6} \mathrm{~S}\right)$ to ${ }^{4} \mathrm{E}\left({ }^{4} \mathrm{D}\right),{ }^{4} \mathrm{~T}_{2}\left({ }^{4} \mathrm{D}\right),\left[{ }^{4} \mathrm{~A}_{1}\left({ }^{4} \mathrm{G}\right),{ }^{4} \mathrm{E}\left({ }^{4} \mathrm{G}\right)\right]$ and ${ }^{4} \mathrm{~T}_{2}\left({ }^{4} \mathrm{G}\right)$, excited levels $[24,25]$. Fig. $2 \mathrm{~d}$ shows the PL spectra of the $\mathrm{SrAl}_{12} \mathrm{O}_{19}: 0.5 \% \mathrm{Mn}^{2+}, 5 \% \mathrm{Gd}^{3+}$ phosphor under the excitation of $424 \mathrm{~nm}$ in the temperature range of $50-300^{\circ} \mathrm{C}$ with a step of $50^{\circ} \mathrm{C}$. It is observed from the spectra that the luminescence intensity decreases with the increment of temperature due to the thermal quenching of the excitation state of $\mathrm{Mn}^{2+}$. The decrease of the intensity may be due to the existence of traps that could store the charge carriers during excitation and thermally release them to compensate the loss of excited carriers after excitation, thus maintaining the good performance of the high temperature spectrum. As a small decrease of about $16.6 \%$ is obtained for the PL intensity when the temperature rises to $300^{\circ} \mathrm{C}$ (Fig. S2), this confirms favorable thermal stability behavior favourable for data storage to prevent undesirable loss. Among the phosphors prepared within this work with different $\mathrm{Gd}^{3+}$ contents (Fig. S3a, S3b), the $\mathrm{SrAl}_{12} \mathrm{O}_{19}: 0.5 \% \mathrm{Mn}^{2+}, 5 \% \mathrm{Gd}^{3+}$ sample features the higher intensity and longer afterglow. After ceasing the irradiation of $254 \mathrm{~nm}$ UV light and by monitoring the $520 \mathrm{~nm}$ emission, $\mathrm{SrAl}_{12} \mathrm{O}_{19}$ : $0.5 \% \mathrm{Mn}^{2+}, 5 \% \mathrm{Gd}^{3+}$ exhibits a persistent luminescence longer than $10 \mathrm{~h}$ ) (Fig. 2e). Such afterglow is also detectable after NIR laser post-irradiation, showing typical OSL [26-28]. 

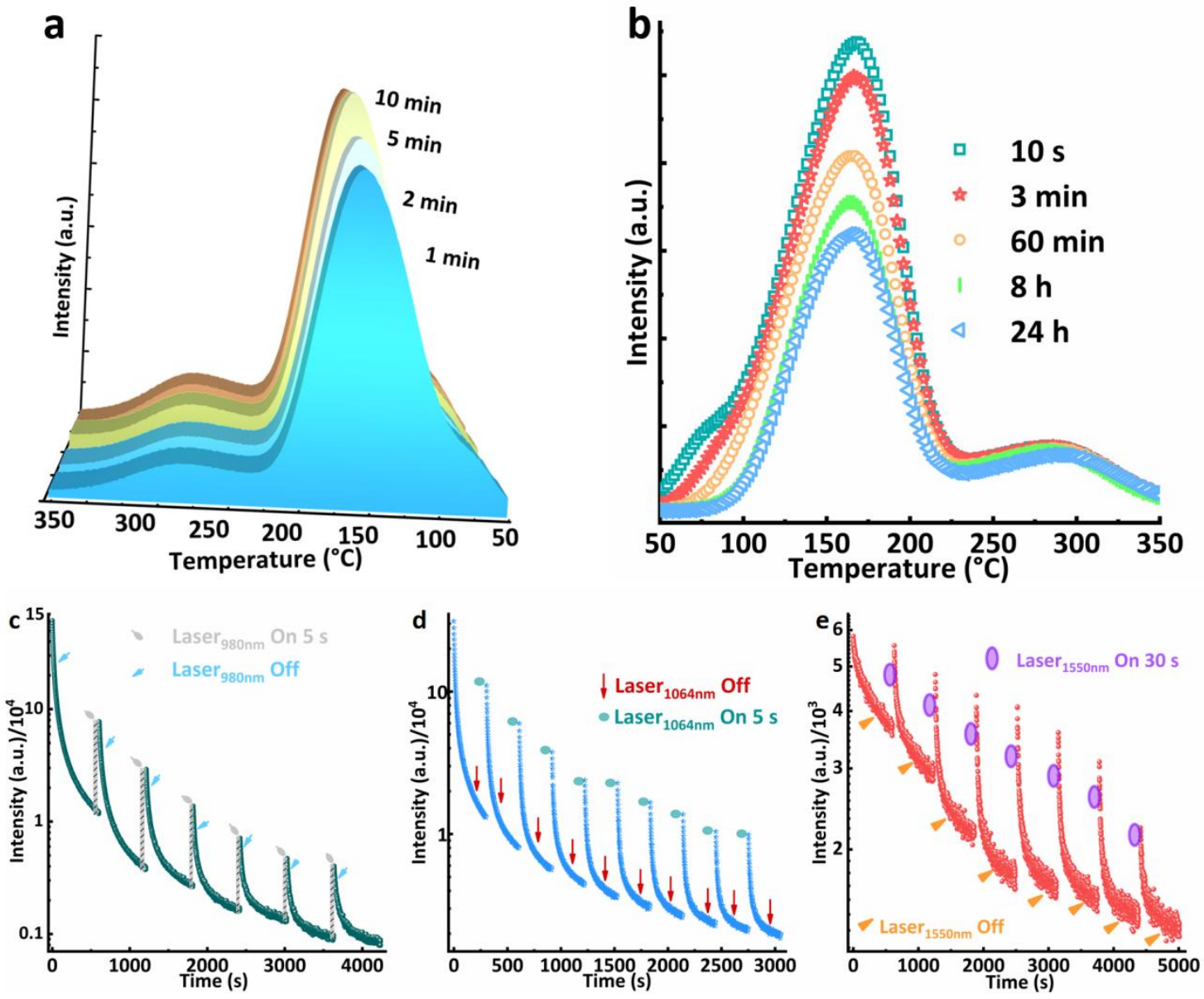

Fig. 3 (a) The phosphor $\mathrm{SrAl}_{12} \mathrm{O}_{19}: 0.5 \% \mathrm{Mn}^{2+}, 5 \% \mathrm{Gd}^{3+}$ of $\mathrm{TL}$ curve measured at $10 \mathrm{~s}$ after the stoppage of irradiation. The phosphor was pre-irradiated by a $30 \mathrm{~W} 254 \mathrm{~nm}$ UV lamp for 1, 2, 5 and $10 \mathrm{~min}$, respectively. (b) TL curves over $50-350^{\circ} \mathrm{C}$ acquired at $10 \mathrm{~s}, 3 \mathrm{~min}, 60 \mathrm{~min}, 8 \mathrm{~h}$ and $24 \mathrm{~h}$ after the stoppage of irradiation. The phosphor $\mathrm{SrAl}_{12} \mathrm{O}_{19}: 0.5 \% \mathrm{Mn}^{2+}, 5 \% \mathrm{Gd}^{3+}$ were pre-irradiated by a $30 \mathrm{~W} 254 \mathrm{~nm}$ UV lamp for $10 \mathrm{~min} ; \mathrm{SrAl}_{12} \mathrm{O}_{19}$ : $0.5 \% \mathrm{Mn}^{2+}, 5 \% \mathrm{Gd}^{3+}$ sample by monitoring $520 \mathrm{~nm}$ emission upon periodic excitation with (c) $980 \mathrm{~nm},(\mathrm{~d})$ $1064 \mathrm{~nm}$ and (e) $1550 \mathrm{~nm}$ lasers. Before the measurements, the phosphor was pre-irradiated using a UV light for $10 \mathrm{~min}$, and then the measures were taken at $24 \mathrm{~h}$ after the stoppage of irradiation.

Fig. 3a-b show the irradiation-time-dependent and interval-time-dependent TL curves of $\mathrm{SrAl}_{12} \mathrm{O}_{19}$ : $0.5 \% \mathrm{Mn}^{2+}$ and $\mathrm{SrAl}_{12} \mathrm{O}_{19}: 0.5 \% \mathrm{Mn}^{2+}, 5 \% \mathrm{Gd}^{3+}$ phosphors. Co-doping with $\mathrm{Gd}^{3+}$ modulates the trap status and intensity in deep (Fig. S4). With the increment of pre-irradiation time and interval time, no any TL peak-shift is observed but the intensity change in all of the TL spectra is obvious for both phosphors. The phosphor of $\mathrm{SrAl}_{12} \mathrm{O}_{19}: 0.5 \% \mathrm{Mn}^{2+}, 5 \% \mathrm{Gd}^{3+}$ exhibited a wide band from room temperature to $350{ }^{\circ} \mathrm{C}$, including three strong peaks at $75{ }^{\circ} \mathrm{C}, 141^{\circ} \mathrm{C}, 172{ }^{\circ} \mathrm{C}$ and $281{ }^{\circ} \mathrm{C}$ (Fig. S5), 
corresponding to three kinds of traps that possibly contributing their trapped carriers to the afterglow. The depth of traps E was roughly estimated by using the empirical Urbach formula [29, 30]

$$
E=\frac{T_{m}}{500}
$$

where $\mathrm{E}$ is trap depth, $\mathrm{T}_{\mathrm{m}}$ is the temperature $(\mathrm{K})$ of each $\mathrm{TL}$ curves peak. Then, estimated trap depths of $\mathrm{SrAl}_{12} \mathrm{O}_{19}: 0.5 \% \mathrm{Mn}^{2+}, 5 \% \mathrm{Gd}^{3+}$ are $0.696 \mathrm{eV}, 0.828 \mathrm{eV}, 0.89 \mathrm{eV}$ and $1.108 \mathrm{eV}$ respectively. This indicates that $\mathrm{SrAl}_{12} \mathrm{O}_{19}: 0.5 \% \mathrm{Mn}^{2+}, 5 \% \mathrm{Gd}^{3+}$ phosphor provide not only a trap at $\sim 0.7 \mathrm{eV}$ depth to generate afterglow at room temperature, but also the relatively deep ones (at about $1 \mathrm{eV}$ ) to store the carriers for OSL applications [31-33].

As shown in Fig. 3c-e, the OSL is observed and it could be repeatedly rejuvenated by the excitation of near IR light. After switching-off the light, the intensity of OSL rapidly falls to a certain value and then becomes stable. Fig. $3 \mathrm{c}$ shows the OSL decay curve of the $\mathrm{SrAl}_{12} \mathrm{O}_{19}$ : $0.5 \% \mathrm{Mn}^{2+}, 5 \% \mathrm{Gd}^{3+}$ sample by monitoring the $520 \mathrm{~nm}$ emission when an $980 \mathrm{~nm}$ laser with periodic on/off was applied as the stimulation source. Obviously, OSL can be repeatedly recovered upon excitation with a $980 \mathrm{~nm}$ laser. After turning off the laser, the OSL rapidly falls down to a certain value and then decays slowly. Notably, the corresponding emission intensity in the OSL decay curve after switching-off the laser is always higher than that in the normal decay one. All these results indicate that deep traps can be release through the conduction band by $980 \mathrm{~nm}$ photons and there is a trap redistribution as part of these traps are recaptured by the shallow traps while others recombine at $\mathrm{Mn}^{2+}$ emitting centers $[34,35]$. As revealed in Fig. 3d and 3e, similar OSL is observed when the $1064 \mathrm{~nm}$ and $1550 \mathrm{~nm}$ NIR lasers excitation is applied as excitation source. Indeed optical and thermal detrapping could require different energy values, but according to the excitation energy, electrons in the shallow traps present different 
kinetics according to the laser wavelength. This could be potentially used in information storage because of highly sensitive OSL to NIR light. For example, optical patterns can be rejuvenated.
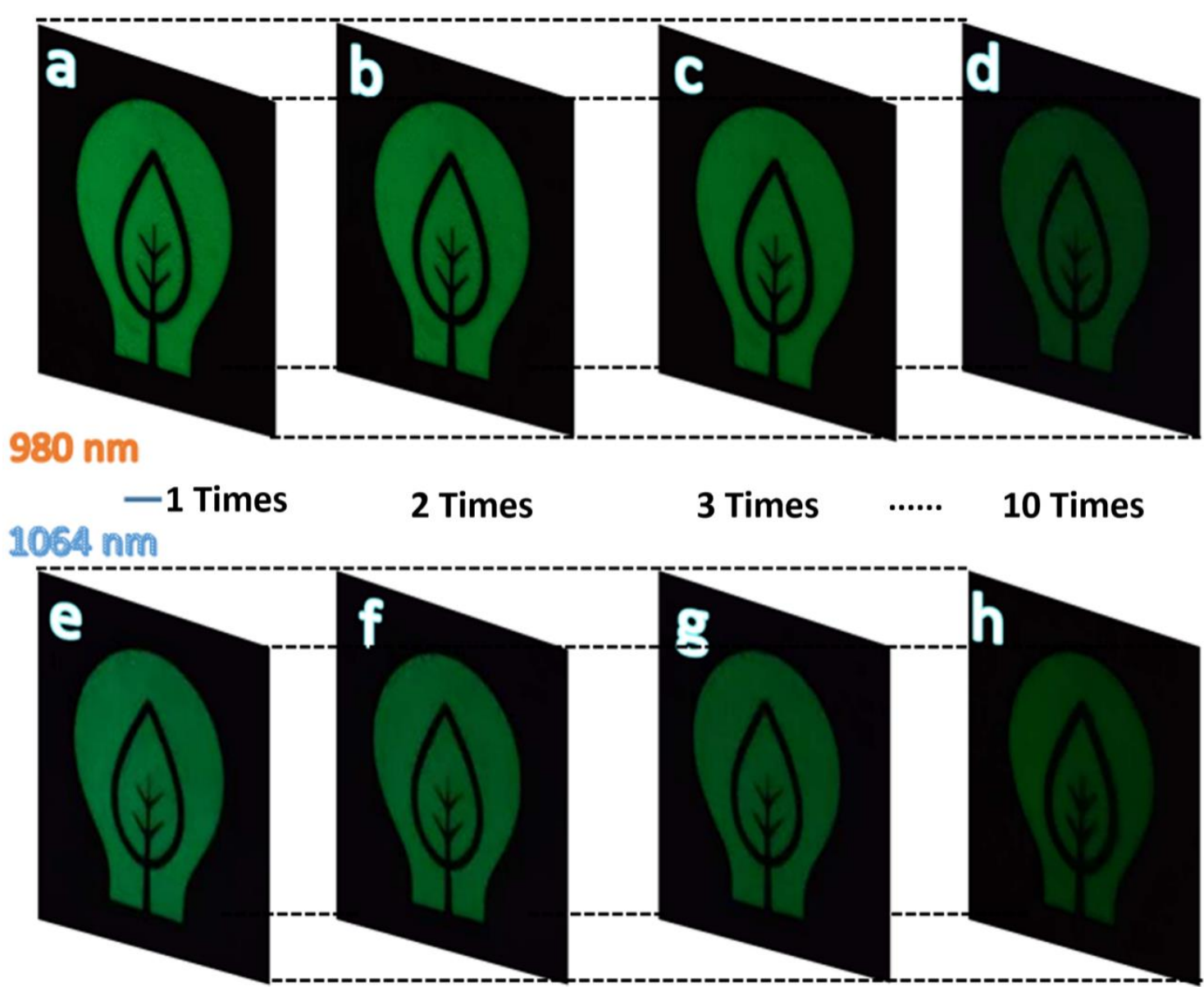

Fig. 4 Images were taken after the first, second, third, and $10^{\text {th }}$ irradiation $5 \mathrm{~s}$ to the samples with $980 \mathrm{~nm}(\mathrm{a}-\mathrm{b})$ and $1064 \mathrm{~nm}$ (e-h) lasers, respectively, the interval time of each laser irradiation is $1 \mathrm{~h}$. The phosphor was preirradiated for 10 min under a $25 \mathrm{~W} 254 \mathrm{~nm}$ UV lamp, and photographed $24 \mathrm{~h}$ after the irradiation stopped.

As shown in Fig. 4, S6 for the schematic of the composite, the composite flat prepared by co-mixing $\mathrm{SrAl}_{12} \mathrm{O}_{19}: 0.5 \% \mathrm{Mn}^{2+}, 5 \% \mathrm{Gd}^{3+}$ and PMMA in a weight ratio of $1: 2$ is excited by patterning a mask on it. The pattern exposure under UV light undergo an information writing process. After aging and fading for 24 hours, there is no more emission. Due the deep traps storage, the patterning area re-appears after scanning by NIR laser at 980 or $1064 \mathrm{~nm}$. The photon emission in the patterns could last for several seconds and vanishes again after switching-off the laser. This process is repeatable for more than 10 
times, until all traps are emptied. Notice that the standard sample without UV pre-excitation does not emit any detectable photon under NIR light [36]. To go further towards information storage, the following set-up was used.

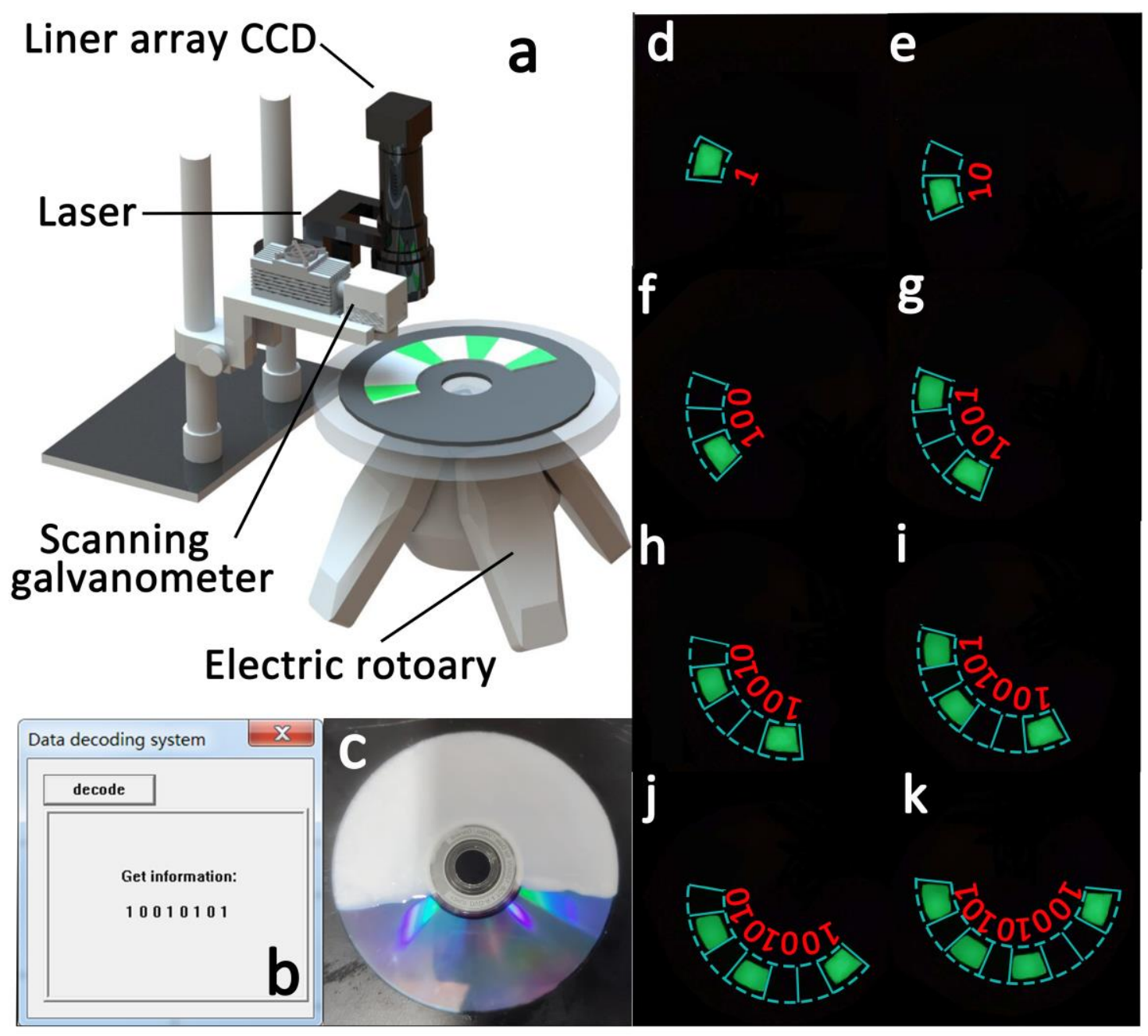

Fig. 5 (a) Schematic illustration of optical disc; (b) The result of decoding the optical information; (c) The disc of optical storage; (d-k) Dynamic optical information reading process.

The information storage can be also realized in digital format, in which data is represented by 0 and 1 . As exhibited in Fig. 5a, a disc-like digital data storage prototype is fabricated with a rotating disc holder, a fixing IR laser and liner array CCD camera. The matrix is made by coating $\operatorname{SrAl}_{12} \mathrm{O}_{19}$ : 
$0.5 \% \mathrm{Mn}^{2+}, 5 \% \mathrm{Gd}^{3+}$ with PMMA on a disc. The unit of the information bit is defined by a certain area depending on the rotation speed. Then units emitting photons are employed to indicate 1 while those without photon emission indicate 0 . As illustrated in Fig. 5 b-k, the data can be written by patterning the disc using $254 \mathrm{~nm}$ UV excitation. After switching-off the excitation, the sequence of the data units can be read by using CCD camera in a rotating process. Prior to the reading process, the data units is irradiated by an IR laser, those pre-excited by UV are read as 1, otherwise are is read as 0 . Then a set of digital data is recorded step by step by a home-make decoding system. For example in Fig. 5 b k, an 8-bit data 10010101 was read and shown in the system correctly, completing an optical data reading process. Such reading process was realized by recording both OSL and its persistent luminescence. In addition, the data capacity is determined by the spatial size of the units. Fig. S7 shows the minimum possible size of the patterns that could be implemented by $6 \mathrm{~mm}$. Normally the smaller of the size renders the higher pattern density and thus a higher data capacity.
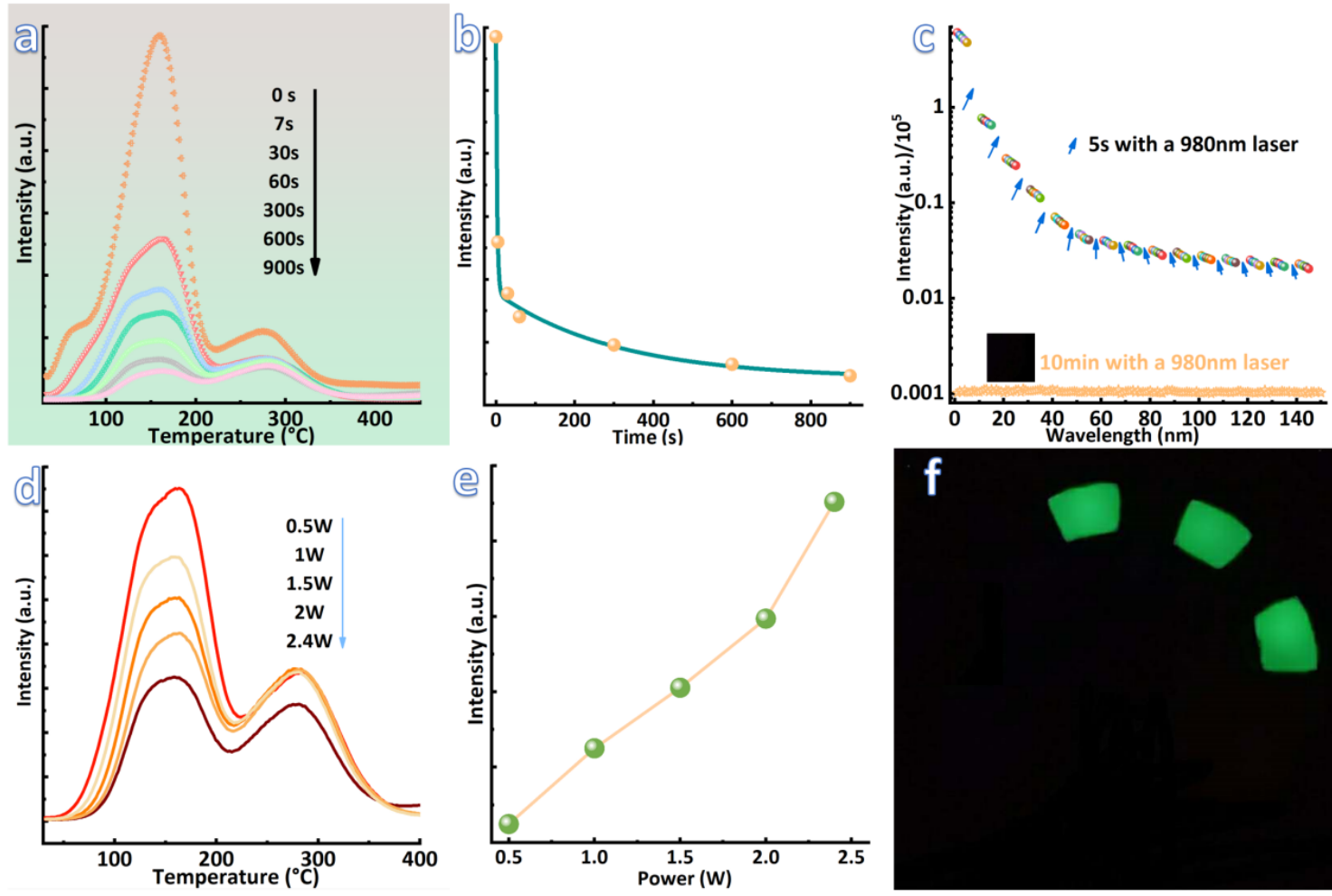
Fig. 6 a) Laser power $(980 \mathrm{~nm}, 2.4 \mathrm{~W})$, TL curves are obtained by irradiating samples at $0 \mathrm{~s}, 7 \mathrm{~s}, 30 \mathrm{~s}, 60 \mathrm{~s}, 300 \mathrm{~s}$, $600 \mathrm{~s}$ and $900 \mathrm{~s}$ respectively. The $\mathrm{SrAl}_{12} \mathrm{O}_{19}: 0.5 \% \mathrm{Mn}^{2+}, 5 \% \mathrm{Gd}^{3+}$ phosphor is pre-irradiated by a $30 \mathrm{~W} 254 \mathrm{~nm}$ UV lamp for $10 \mathrm{~min}$; b) TL intensity of fig. $6 \mathrm{a}$ and its fitting curve when the temperature is $163^{\circ} \mathrm{C}$; c) $\mathrm{SrAl}_{12} \mathrm{O}_{19}$ : $0.5 \% \mathrm{Mn}^{2+}, 5 \% \mathrm{Gd}^{3+}$ sample by monitoring $520 \mathrm{~nm}$ emission upon periodic excitation with $980 \mathrm{~nm}$ lasers $(5 \mathrm{~s}$ and 10min). Before measurements, the phosphor was pre-irradiated using a UV light for $10 \mathrm{~min}$, and then the measures were taken at $24 \mathrm{~h}$ after the stoppage of irradiation. d) TL curves of samples irradiated by different laser powers $(0.5 \mathrm{w}, 1 \mathrm{w}, 1.5 \mathrm{w} 2 \mathrm{w}$ and $2.4 \mathrm{w})$ for $10 \mathrm{~min}$. The phosphor $\mathrm{SrAl}_{12} \mathrm{O}_{19}: 0.5 \% \mathrm{Mn}^{2+}, 5 \% \mathrm{Gd}^{3+}$ were preirradiated by a $30 \mathrm{~W} 254 \mathrm{~nm}$ UV lamp for $10 \mathrm{~min}$; e) TL intensity of fig. $6 \mathrm{~d}$ when the temperature is $163^{\circ} \mathrm{C}$; f) Dynamic optical information erasing process.

The data on disc can be erased by increasing the irradiation time of IR laser. In this process, the number of the trapped carriers is kept decreasing until the OSL or TL is not readable. Fig. 6a shows TL curves of the sample which is sufficiently excited by UV and erased by IR laser irradiation for $0 \mathrm{~s}, 7 \mathrm{~s}, 30 \mathrm{~s}$, 60s, 300s, 600s and 900s respectively. With the increment of irradiation time, the intensity of TL progressively decreases. The TL intensity can be fitted by the double-exponential formula (Fig. $6 \mathrm{~b}$ and Eq S2 in supporting information), by monitoring $520 \mathrm{~nm}$ emission upon periodic excitation with 980 $\mathrm{nm}$ lasers (5s and 10min). When the phosphor is irradiated with a $980 \mathrm{~nm}$ laser for $10 \mathrm{~min}$, no optical signal of afterglow delay is detected and used as a reference line (Fig. 6c). Moreover, the data can be also erased by increasing the power of laser. Fig. $6 \mathrm{~d}$ shows TL curves of samples irradiated by different laser power $(0.5 \mathrm{w}, 1 \mathrm{w}, 1.5 \mathrm{w} 2 \mathrm{w}$ and $2.4 \mathrm{w})$ for $10 \mathrm{~min}$. With the increase of laser power, TL intensity decreases gradually. TL intensity is proportional to the strength (fig. 6e), indicating a fast data erasable process during the optical information storage. For exemple, as shown in Fig. $6 f$, the optical data in the highest bit units of 10010101 is erased. Then data become 00010101. Using a moderate power laser, the digital data is erasable in high-speed disc rotation, getting ready for another writing process. This was an example of the possible use of the system for memory applications. 


\section{Conclusions}

In summary, we proposed an novel information storage prototype using OSL phosphor which was realized by $\mathrm{SrAl}_{12} \mathrm{O}_{19}: \mathrm{Mn}^{2+}, \mathrm{Gd}^{3+}$. By rational testing of the PL, OSL, and TL, the scientific mechanism of information storage prototype has been expounded and exhibited entirely. PL with afterglow and OSL at $520 \mathrm{~nm}$ emission wavelength were observed. Due to the deep traps in the materials, the OSL was induced by NIR light excitation (980nm, 1064nm, 1550nm) by taking out parts of the trapped carriers, rendering a readable and rewritable data storage ability by photon energy conversion and management. For the first time, a proof-of-concept study to develop an OSL material with a disc-like digital data storage prototype is fabricated with a rotating disc holder and completing an optical data reading process. In addition, the data on disc can be erased by increasing the irradiation time of IR laser. Such reading process was realized by recording both OSL and its persistent luminescence. It provides a feasible example for future writing-storing-readout-erasing-rewriting integration optical information storage application.

\section{Acknowledgments}

This work was financially supported by the National Natural Science Foundation of China (Grant No. 51972065). 


\section{References}

[1] Y. Gao, R. F. Li, W. Zheng, X. Y. Shang, J. J. Wei, M. R. Zhang, J. Xu, W. W. You, Z. Chen, X. Y. Chen, Broadband NIR photostimulated luminescence nanoprobes based on $\mathrm{CaS}: \mathrm{Eu}^{2+}, \mathrm{Sm}^{3+}$ nanocrystals, Chem. Sci., 10 (2019) 5452.

[2] R. Hu, Y. Zhang, Y. Zhao, X. Wang, G. R. Li, C. Y. Wang, UV-Vis-NIR broadbandphotostimulated luminescence of $\mathrm{LiTaO}_{3}: \mathrm{Bi}^{3+}$ longpersistent phosphor and the optical storage properties, Chem. Eng. J. 392 (2020) 124807.

[3] Z. B. Wang, W. X. Wang, H. Zhou, J. C. Zhang, S. L. Peng, Z. Y. Zhao, Y. H. Wang, Superlong and Color-Tunable Red Persistent Luminescence and Photostimulated Luminescence Properties of $\mathrm{NaCa}_{2} \mathrm{GeO}_{4} \mathrm{~F}: \mathrm{Mn}^{2+}, \mathrm{Yb}^{3+}$ Phosphor, Inorg. Chem. 55 (2016) 12822-12831.

[4] Y. X. Zhuang, L. Wang, Y. Lv, T.-L. Zhou, R.-J. Xie, Optical Data Storage and Multicolor Emission Readout on Flexible Films Using Deep-Trap Persistent Luminescence Materials, Adv. Funct. Mater. 28 (2018) 1705769.

[5] F. Liu, W. Z. Yan, Y.-J. Chuang, Z. P. Zhen, J. Xie, Z. W. Pan, Photostimulated near-infrared persistent luminescence as a new optical read-out from $\mathrm{Cr}^{3+}$-doped $\mathrm{LiGa}_{5} \mathrm{O}_{8}$, Sci. Rep. 3 (2013) 1554.

[6] Y. Li, S. F. Zhou, Y. Y. Li, K. Sharafudeen, Z. J. Ma, G. P. Dong, M. Y. Peng, J. R. Qiu, Long persistent and photo-stimulated luminescence in $\mathrm{Cr}^{3+}$-doped $\mathrm{Zn}-\mathrm{Ga}-\mathrm{Sn}-\mathrm{O}$ phosphors for deep and reproducible tissue imaging, J. Mater. Chem. C, 2 (2014) 2657.

[7] W. H. Li, Y. X. Zhuang, P. Zheng, T.-L. Zhou, J. Xu, J. Ueda, S. Tanabe, L. Wang, R.-J. Xie, Tailoring Trap Depth and Emission Wavelength in $\mathrm{Y}_{3} \mathrm{Al}_{5-\mathrm{x}} \mathrm{Ga}_{\mathrm{x}} \mathrm{O}_{12}: \mathrm{Ce}^{3+}, \mathrm{V}^{3+}$ Phosphor-in-Glass Films for Optical Information Storage, ACS Appl. Mater. Interfaces 10 (2018) 27150-27159. 
[8] J. Xu, D. Murata, J. Ueda, B. Viana, S. Tanabe, Toward Rechargeable Persistent Luminescence for the First and Third Biological Windows via Persistent Energy Transfer and Electron Trap Redistribution, Inorg. Chem. 57 (2018) 5194-5203.

[9] X. Y. Sun, J. H. Zhang, X. Zhang, Y. S. Luo, Z. D. Hao, X.-J. Wang, Effect of retrapping on photostimulated luminescence in $\mathrm{Sr}_{3} \mathrm{SiO}_{5}: \mathrm{Eu}^{2+}$, Dy ${ }^{3+}$ phosphor, J. Appl. Phys. 105 (2009) 013501.

[10] S. K Sharma, D. Gourier, E. Teston, D. Scherman, C. Richard, B. Viana, Persistent luminescence induced by near infra-red photostimulation in chromium-doped zinc gallate for in vivo optical imaging, Opt. Mater. 63 (2017) 51-58.

[11] R. Kang, X. J. Dou, H. W. Lian, Y. Li, $\mathrm{SrAl}_{12} \mathrm{O}_{19}: \mathrm{Fe}^{3+}$ @ 3- aminopropyl triethoxysilane: Ambient aqueous stable near- infrared persistent luminescent nanocomposites, J Am Ceram Soc. 103 (2020) 258-265.

[12] Z. Y. Zhang, Y. H. Zhang, X. L. Li, J. H. Xu, Y. Huang, The relationships between crystal structure of alkaline earth metal hexagonal aluminate and $4 \mathrm{f}-5 \mathrm{~d}$ transitions of $\mathrm{Ce}^{3+}$ and $\mathrm{Tb}^{3+}$ ions, $\mathrm{J}$. Non-Cryst. Solids 354 (2008) 1943-1947.

[13] M. Y. Aoki, N. Takeuchi, Y. Murayama, New long phosphorescent phosphor with high brightness, $\mathrm{SrAI}_{2} \mathrm{O}_{4}: \mathrm{Eu}^{2+}, \mathrm{Dy}^{3+}$, J. Electrochem. Soc. 143 (1996) 2670-2673.

[14] T. T. Cui, P. C. Ma, Y. Sheng, K. Y. Zheng, X. Q. Zhou, C. Y. Xu, H. F. Zou, Y. H. Song, Preparation of $\mathrm{CaAl}_{2} \mathrm{O}_{4}: \mathrm{Eu}^{2+}, \mathrm{Nd}^{3+}$ and $\mathrm{SrAl}_{2} \mathrm{O}_{4}: \mathrm{Eu}^{2+}, \mathrm{Dy}^{3+}$ long afterglow luminescent materials using oil shale ash, Opt. Mater. 67 (2017) 84-90.

[15] R. Kang, J. M. Nie, X. J. Dou, S. A. Zhang, G. F. Ju, L. Chen ,Y. H. Hu, Y. Li, Tunable NIR long persistent luminescence and discovery of trap-distribution-dependent excitation enhancement in transition metal doped weak-crystal-field $\mathrm{CaZnGe}_{2} \mathrm{O}_{6}$, J. Alloy. Compd. 735 (2018) 692-699. 
[16] X. H. Lin, R. L. Zhang, X. M. Tian, Y. Li, B. S. Du, J. M. Nie, Z. Z. Li, L. Chen, J. J. Ren, J. R. Qiu, Y. H. Hu, Coordination geometry-dependent multi-band emission and atypically deep-trapdominated NIR persistent luminescence from chromium-doped aluminates, Adv. Optical Mater. 6 (2018) 1701161.

[17] Z. W. Pan, Y.-Y. Lu, F. Liu, Sunlight-activated long-persistent luminescence in the near-infrared from $\mathrm{Cr}^{3+}$-doped zinc gallogermanates, Nat. Mater. 11 (2012) 59-63.

[18] H. H. Lin, G. X. Bai, T. Yu, M.-K. Tsang, Q. Y. Zhang, J. H. Hao, Site occupancy and nearinfrared luminescence in $\mathrm{Ca}_{3} \mathrm{Ga}_{2} \mathrm{Ge}_{3} \mathrm{O}_{12}: \mathrm{Cr}^{3+}$ persistent phosphor, Adv. Optical Mater. 5 (2017) 1700227.

[19] B. Viana, S. K Sharma, D. Gourier, T. Maldiney, E. Teston, D. Scherman, C. Richard, Long term in vivo imaging with $\mathrm{Cr}^{3+}$ doped spinel nanoparticles exhibiting persistent luminescence, J. Lumin. 170 (2016) 879-887.

[20] Z. G. Nie, J. H. Zhang, X. Zhang, X. G. Ren, W. H. Di, G. B. Zhang, D. H. Zhang, X.-J Wang, Spectroscopic investigation of $\mathrm{CaAl}_{12} \mathrm{O}_{19}: \mathrm{M}^{3+}$ upon UV/vacuum-UV excitation: a comparison with $\mathrm{SrAl}_{12} \mathrm{O}_{19}: \mathrm{M}^{3+}(\mathrm{M}=\mathrm{Pr}, \mathrm{Cr})$, J. Phys.: Condens. Matter 19 (2007) 076204.

[21] X. H. Lin, Y. Li, S. Saravanakumar, Q. Tang, S. A. Zhang, X. P. Gao, Y.H. Hua, K. Huang, G. Han, Sunlight-operable light converting smart windows for fertilizer-freeplant growth enhancement, Nano Today 34 (2020) 100918.

[22] S. Fischer, J. Roeser, T. Lin; R. H. DeBlock, J. Lau, B. S. Dunn, F. Hoffmann, M. Fr oba, A. Thomas, S. H.Tolbert, A metal-organic framework with tetrahedral aluminate sites as a single-Ion Li+ solid electrolyte, Angew.Chem. Int. Ed. 57 (2018) 16683-16687. 
[23] H. J. Guo, Y. H. Wang, W. B. Chen, W. Zeng, S. C. Han, G. Li, Y. Y. Li, Controlling and revealing trap distributions of $\mathrm{Ca}_{6} \mathrm{BaP}_{4} \mathrm{O}_{17}: \mathrm{Eu}^{2+}, \mathrm{R}^{3+}(\mathrm{R}=\mathrm{Dy}, \mathrm{Tb}, \mathrm{Ce}, \mathrm{Gd}, \mathrm{Nd})$ by codoping different trivalent lanthanides, J. Mater. Chem. C 3 (2015) 11212-11218.

[24] Z. C. Zhang, C. G. Ma, R. Gautier, M. S. Molokeev, Q. L. Liu, Z. G Xia, Structural confinement toward giant enhancement of red emission in $\mathrm{Mn}^{2+}$-based phosphors, Adv. Funct. Mater. 28 (2018) 1804150.

[25] X. S. Tang, W. W. Chen, Z. Z. Liu, J. Du, Z. Q. Yao, Y. Huang, C. Chen, Z. Q. Yang, T. C. Shi, W. Hu, Z. G. Zang, Y. Chen, Y. X. Leng, Ultrathin, core-shell structured $\mathrm{SiO}_{2}$ coated $\mathrm{Mn}^{2+}$-doped perovskite quantum dots for bright white light-emitting diodes, Small 15 (2019) 1900484.

[26] Z. F. Wu, C. Y. Zhou, B. Y. Zu, Y. S. Li, X. C. Dou, Contactless and rapid discrimination of improvised explosives realized by $\mathrm{Mn}^{2+}$ doping tailored $\mathrm{ZnS}$ nanocrystals, Adv. Funct. Mater. 6 (2016) 4578-4586.

[27] E. H. Song, Z. T. Chen , M. Wu , S. Ding, S. Ye, S. F. Zhou , Q. Y. Zhang, Room-temperature wavelength-tunable single-band upconversion luminescence from $\mathrm{Yb}^{3+} / \mathrm{Mn}^{2+}$ codoped fluoride perovskites $\mathrm{ABF}_{3}$, Adv. Optical Mater. 4 (2016) 798-806.

[28] F. Li, Z. G. Xia, Q. L. Liu, Controllable synthesis and optical properties of $\mathrm{ZnS}: \mathrm{Mn}^{2+} / \mathrm{ZnS} / \mathrm{ZnS}: \mathrm{Cu}^{2+} / \mathrm{ZnS}$ core/multi-shell quantum dots towards efficient white light emission, ACS Appl. Mater. Interfaces 9 (2017) 9833-9839.

[29] Y. Li, M. Geceviciusa, J. R. Qiu, Long persistent phosphors-from fundamentals to applications, Chem. Soc. Rev. 45 (2016) 2090. 
[30] L. M. Fan, Y. Li, Y. H. Hu, F. H. Xue, S. A. Zhang, G. F. Ju, X. H. Lin, A co-doping influence towards enhanced persistent duration of long persistent phosphors, J Mater Sci: Mater Electron,28 (2017) 16842-16846.

[31] Y. J. Liang, F. Liu, Y. F. Chen, K. N. Sun, Z. W. Pan, Long persistent luminescence in the ultraviolet in $\mathrm{Pb}^{2+}$-doped $\mathrm{Sr}_{2} \mathrm{MgGe}_{2} \mathrm{O}_{7}$ persistent phosphor, Dalton Trans. 45 (2016) 1322-1326.

[32] T. Maldiney, A. Bessière, J. Seguin, E. Teston, S. K. Sharma,B. Viana, A. J. J. Bos, P. Dorenbos, M. Bessodes, D. Gourier, D. Scherman, C. Richard, The in vivo activation of persistent nanophosphors for optical imaging of vascularization, tumours and grafted cells, Nat. Mater. 13 (2014) 418-426.

[33] S.-Q. Wu, C.-X. Yang, X.-P. Yan, A dual-functional persistently luminescent nanocomposite enables engineering of mesenchymal stem cells for homing and gene therapy of glioblastoma, Adv. Funct. Mater. 21 (2017)1604992.

[34] Y. Y. Jiang, J. C. Li, X. Zhen, C. Xie, K. Y Pu, Dual-peak absorbing semiconducting copolymer nanoparticles for first and second near-infrared window photothermal therapy: a comparative study. Adv. Mater. 30 (2018) 1705980.

[35] E. H. Song, J. L. Wang, S. Ye, X.-B. Yang, M. Y. Peng, Q. Y. Zhang, L. Wondraczek, Wavelength-tunability and multiband emission from single-Site $\mathrm{Mn}^{2+}$ doped $\mathrm{CaO}$ through antiferromagnetic coupling and tailored superexchange reactions, Adv. Optical Mater. 5 (2017) 1700070.

[36] D. Liu, L. F. Yuan, Y. H. Jin, H. Y. Wu, Y. Lv, G. T. Xiong, G. F. Ju, L.Chen, S. H. Yang, Y. H $\mathrm{Hu}$, Tailoring multidiMmensional traps for rewritable multilevel optical data storage, ACS Appl. Mater. Interfaces 11 (2019) 35023-35029. 


\section{Table}

Table 1. Potential phosphors for optical information storage

\begin{tabular}{c|c|c|c}
\hline Materials & Erasable & Trap depths (eV) & Luminous band (nm) \\
\hline $\mathrm{CaS}_{\mathrm{E}: \mathrm{Eu}^{2+}, \mathrm{Sm}[1]}$ & --- & 0.76 & $500-800$ \\
$\mathrm{LiTaO}_{3}: \mathrm{Bi}[2]$ & --- & $0.64-0.76$ & $300-600$ \\
$\mathrm{NaCa}_{2} \mathrm{GeO}_{4} \mathrm{~F}: \mathrm{Mn}, \mathrm{Yb}[3]$ & --- & $0.52-1.15$ & $500-800$ \\
$\left(\mathrm{Sr}_{1-\mathrm{x}} \mathrm{Ba}_{\mathrm{x}}\right) \mathrm{Si}_{2} \mathrm{O}_{2} \mathrm{~N}_{2}: \mathrm{Eu} / \mathrm{Yb}, \mathrm{Dy}[4]$ & thermal & $1.12-1.31$ & $450-750$ \\
$\mathrm{LiGa}_{5} \mathrm{O}_{8}: \mathrm{Cr}[5]$ & --- & $0.8-0.95$ & $700-800$ \\
$\mathrm{Zn}_{3} \mathrm{Ga}_{2} \mathrm{SnO}_{8}: \mathrm{Cr}[6]$ & --- & 1.25 & $650-800$ \\
$\mathrm{Y}_{3} \mathrm{Al}_{5-\mathrm{x}} \mathrm{Ga}_{\mathrm{x}} \mathrm{O}_{12}: \mathrm{Ce}, \mathrm{V}[7]$ & thermal & $1.2-1.6$ & $450-750$ \\
$\mathrm{YAGG}_{\mathrm{HA}} \mathrm{Er}, \mathrm{Cr}[8]$ & --- & $0.6-0.82$ & $600-1700$ \\
$\mathrm{Sr}_{3} \mathrm{SiO}_{5}: \mathrm{Eu}, \mathrm{Dy}[9]$ & thermal & $0.6-1.09$ & $450-700$ \\
$\mathrm{ZnGa}_{2} \mathrm{O}_{4}: \mathrm{Cr}[10]$ & Thermal/Photon & $0.6-1$ & $650-750$ \\
\hline
\end{tabular}




\section{Figure captions}

Fig. 1 Diagrammatic rewritable information storage based on OSL.

Fig. 2 (a) Schematic diagram of $\mathrm{SrAl}_{12} \mathrm{O}_{19}$ structure and coordination environments of the $\mathrm{Al}^{3+}$ cations.

(b) XRD patterns for $\mathrm{SrAl}_{12} \mathrm{O}_{19}: 0.5 \% \mathrm{Mn}^{2+}, 5 \% \mathrm{Gd}^{3+}$ and $\mathrm{SrAl}_{12} \mathrm{O}_{19}: 0.5 \% \mathrm{Mn}^{2+}$ phosphors. (c) Photoluminescence spectrum and photoluminescence excitation spectrum of $\mathrm{SrAl}_{12} \mathrm{O}_{19}: 0.5 \% \mathrm{Mn}^{2+}$, $5 \% \mathrm{Gd}^{3+}$ and $\mathrm{SrAl}_{12} \mathrm{O}_{19}: 0.5 \% \mathrm{Mn}^{2+}$ phosphors; (d) Variable temperature PL emission spectra of $\mathrm{SrAl}_{12} \mathrm{O}_{19}: 0.5 \% \mathrm{Mn}^{2+}, 5 \% \mathrm{Gd}^{3+}$ phosphor under $424 \mathrm{~nm}$ excitation wavelength. (e) Afterglow intensity monitored at $520 \mathrm{~nm}$ of $\mathrm{Mn}^{2+}$ in $\mathrm{SrAl}_{12} \mathrm{O}_{19}: 0.5 \% \mathrm{Mn}^{2+}, 5 \% \mathrm{Gd}^{3+}$ phosphor after being pre-irradiated by $30 \mathrm{~W}$ UV lamp for $10 \mathrm{~min}$.

Fig. 3 (a) The phosphor $\mathrm{SrAl}_{12} \mathrm{O}_{19}: 0.5 \% \mathrm{Mn}^{2+}, 5 \% \mathrm{Gd}^{3+}$ of TL curve measured at $10 \mathrm{~s}$ after the stoppage of irradiation. The phosphor was pre-irradiated by a $30 \mathrm{~W} 254 \mathrm{~nm}$ UV lamp for 1, 2, 5 and $10 \mathrm{~min}$, respectively. (b) TL curves over $50-350{ }^{\circ} \mathrm{C}$ acquired at $10 \mathrm{~s}, 3 \mathrm{~min}, 60 \mathrm{~min}, 8 \mathrm{~h}$ and $24 \mathrm{~h}$ after the stoppage of irradiation. The phosphor $\mathrm{SrAl}_{12} \mathrm{O}_{19}: 0.5 \% \mathrm{Mn}^{2+}, 5 \% \mathrm{Gd}^{3+}$ were pre-irradiated by a $30 \mathrm{~W}$ $254 \mathrm{~nm}$ UV lamp for $10 \mathrm{~min} ; \mathrm{SrAl}_{12} \mathrm{O}_{19}: 0.5 \% \mathrm{Mn}^{2+}, 5 \% \mathrm{Gd}^{3+}$ sample by monitoring $520 \mathrm{~nm}$ emission upon periodic excitation with (c) $980 \mathrm{~nm}$, (d) 1064nm and (e) 1550nm lasers. Before the measurements, the phosphor was pre-irradiated using a UV light for $10 \mathrm{~min}$, and then the measures were taken at $24 \mathrm{~h}$ after the stoppage of irradiation. 
Fig. 4 Images were taken after the first, second, third, and $10^{\text {th }}$ irradiation $5 \mathrm{~s}$ to the samples with 980 $\mathrm{nm}(\mathrm{a}-\mathrm{b})$ and $1064 \mathrm{~nm}(\mathrm{e}-\mathrm{h})$ lasers, respectively, the interval time of each laser irradiation is $1 \mathrm{~h}$. The phosphor was pre-irradiated for 10 min under a $25 \mathrm{~W} 254 \mathrm{~nm}$ UV lamp, and photographed $24 \mathrm{~h}$ after the irradiation stopped.

Fig. 5 (a) Schematic illustration of optical disc; (b) The result of decoding the optical information;

(c) The disc of optical storage; (d-k) Dynamic optical information reading process.

Fig. 6 a) Laser power $(980 \mathrm{~nm}, 2.4 \mathrm{~W})$, TL curves are obtained by irradiating samples at $0 \mathrm{~s}, 7 \mathrm{~s}, 30 \mathrm{~s}$, $60 s, 300$ s, 600s and 900s respectively. The $\mathrm{SrAl}_{12} \mathrm{O}_{19}: 0.5 \% \mathrm{Mn}^{2+}, 5 \% \mathrm{Gd}^{3+}$ phosphor is pre-irradiated by a $30 \mathrm{~W} 254 \mathrm{~nm}$ UV lamp for $10 \mathrm{~min}$; b) TL intensity of fig. $6 \mathrm{a}$ and its fitting curve when the temperature is $163^{\circ} \mathrm{C}$; c) $\mathrm{SrAl}_{12} \mathrm{O}_{19}: 0.5 \% \mathrm{Mn}^{2+}, 5 \% \mathrm{Gd}^{3+}$ sample by monitoring $520 \mathrm{~nm}$ emission upon periodic excitation with $980 \mathrm{~nm}$ lasers (5s and 10min). Before measurements, the phosphor was preirradiated using a UV light for $10 \mathrm{~min}$, and then the measures were taken at $24 \mathrm{~h}$ after the stoppage of irradiation. d) TL curves of samples irradiated by different laser powers $(0.5 \mathrm{w}, 1 \mathrm{w}, 1.5 \mathrm{w} 2 \mathrm{w}$ and $2.4 \mathrm{w})$ for $10 \mathrm{~min}$. The phosphor $\mathrm{SrAl}_{12} \mathrm{O}_{19}: 0.5 \% \mathrm{Mn}^{2+}, 5 \% \mathrm{Gd}^{3+}$ were pre-irradiated by a $30 \mathrm{~W} 254 \mathrm{~nm} \mathrm{UV}$ lamp for $10 \mathrm{~min}$; e) $\mathrm{TL}$ intensity of fig. $6 \mathrm{~d}$ when the temperature is $163^{\circ} \mathrm{C}$; f) Dynamic optical information erasing process. 


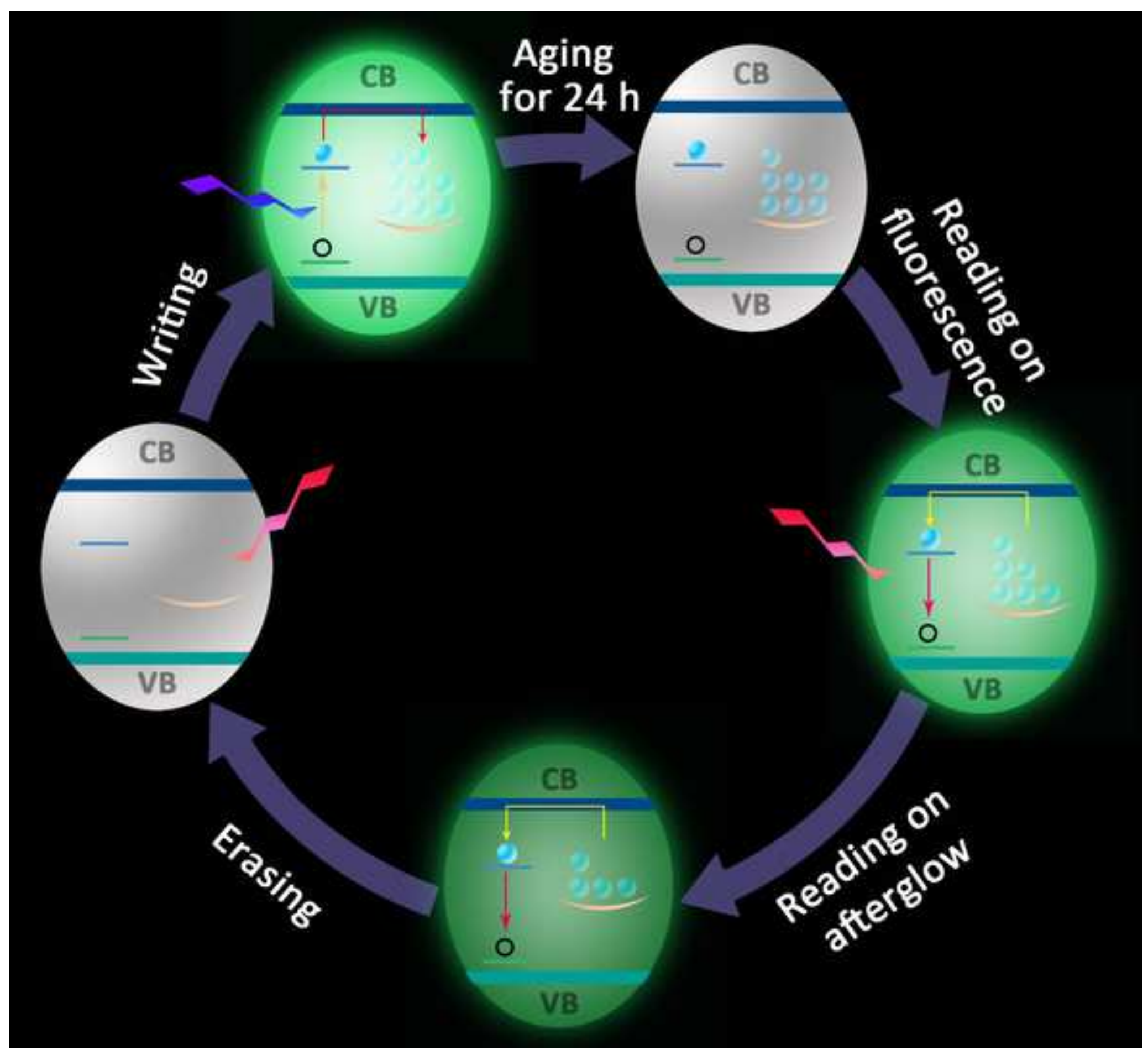



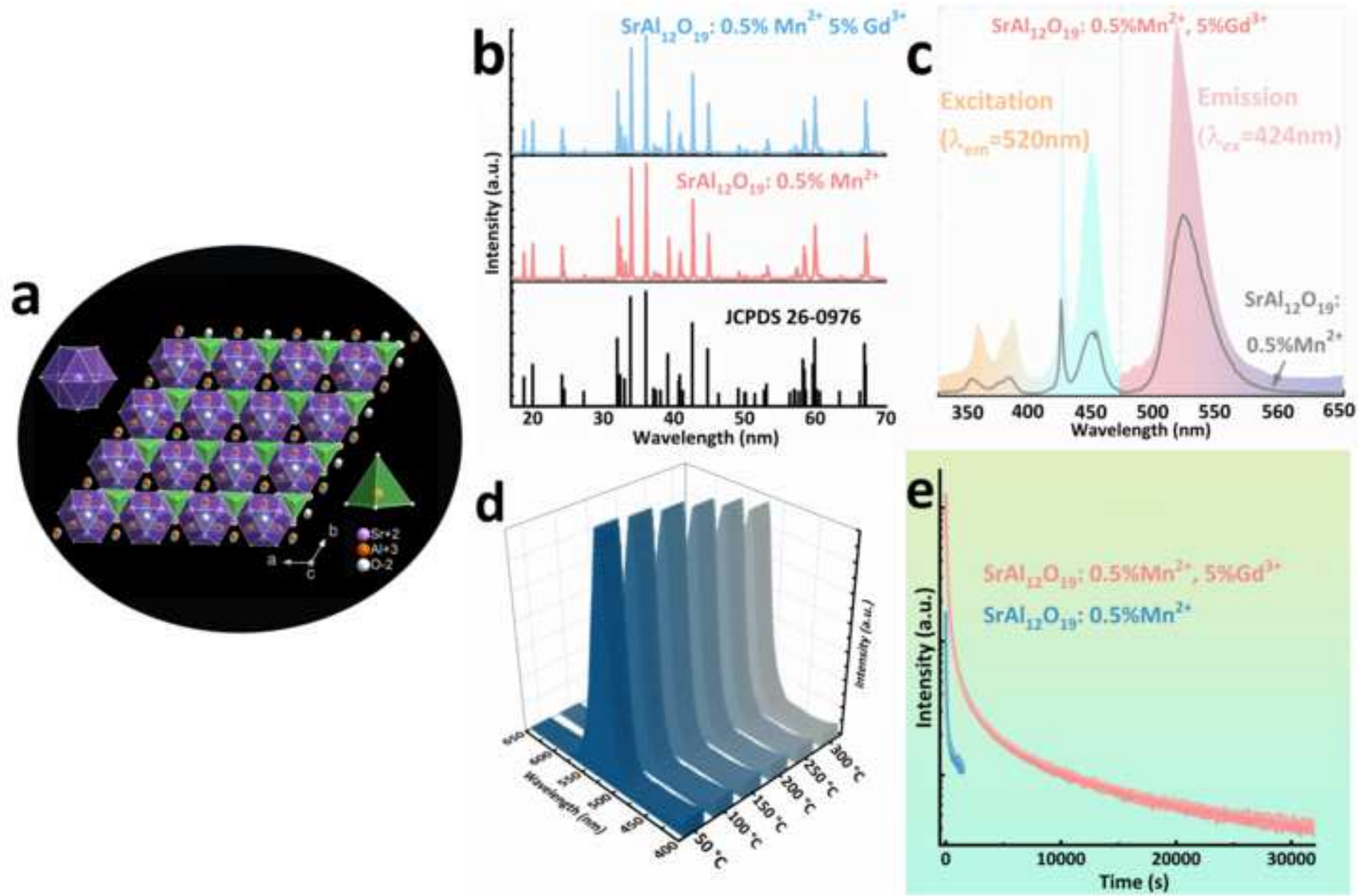

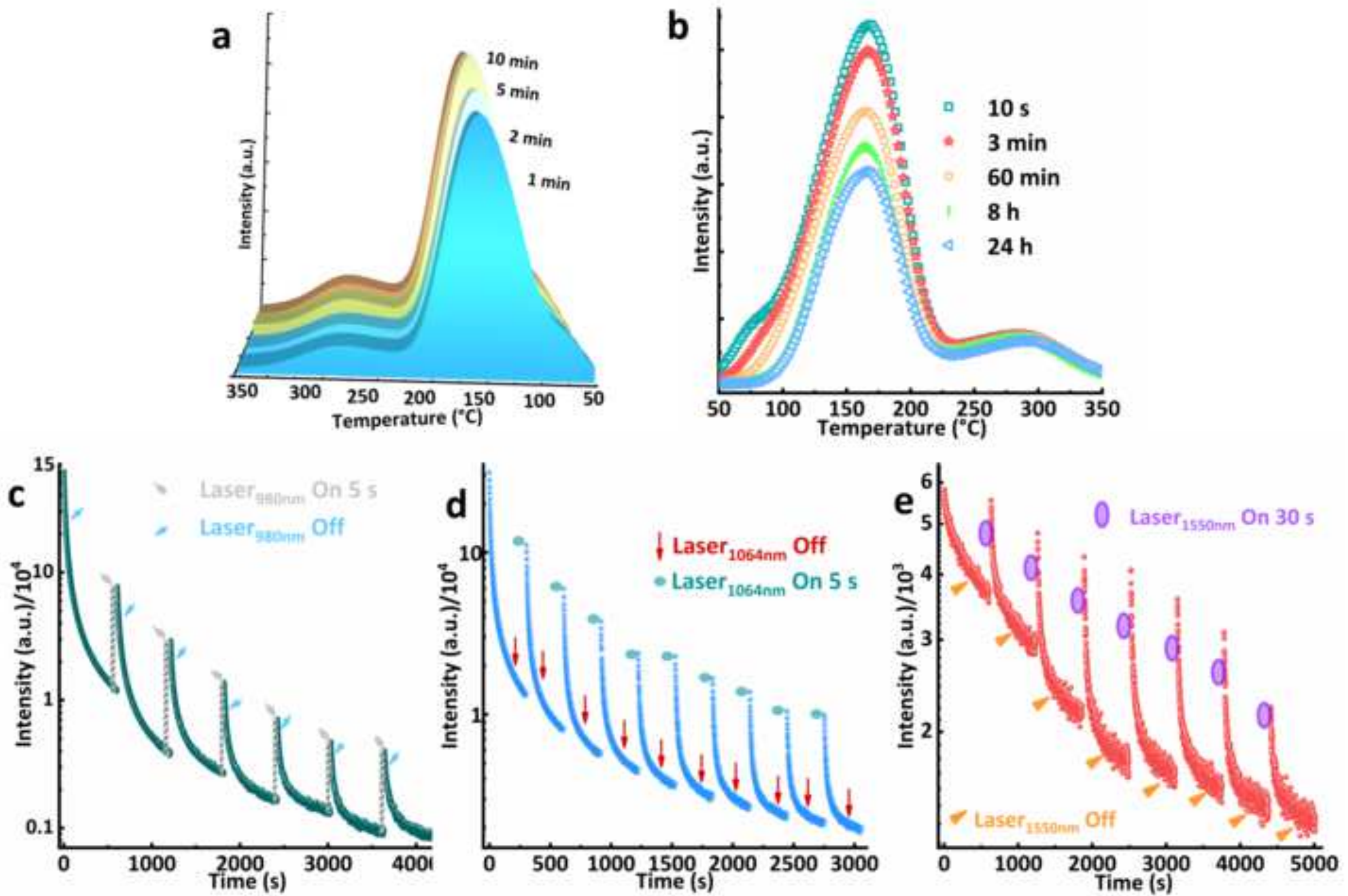


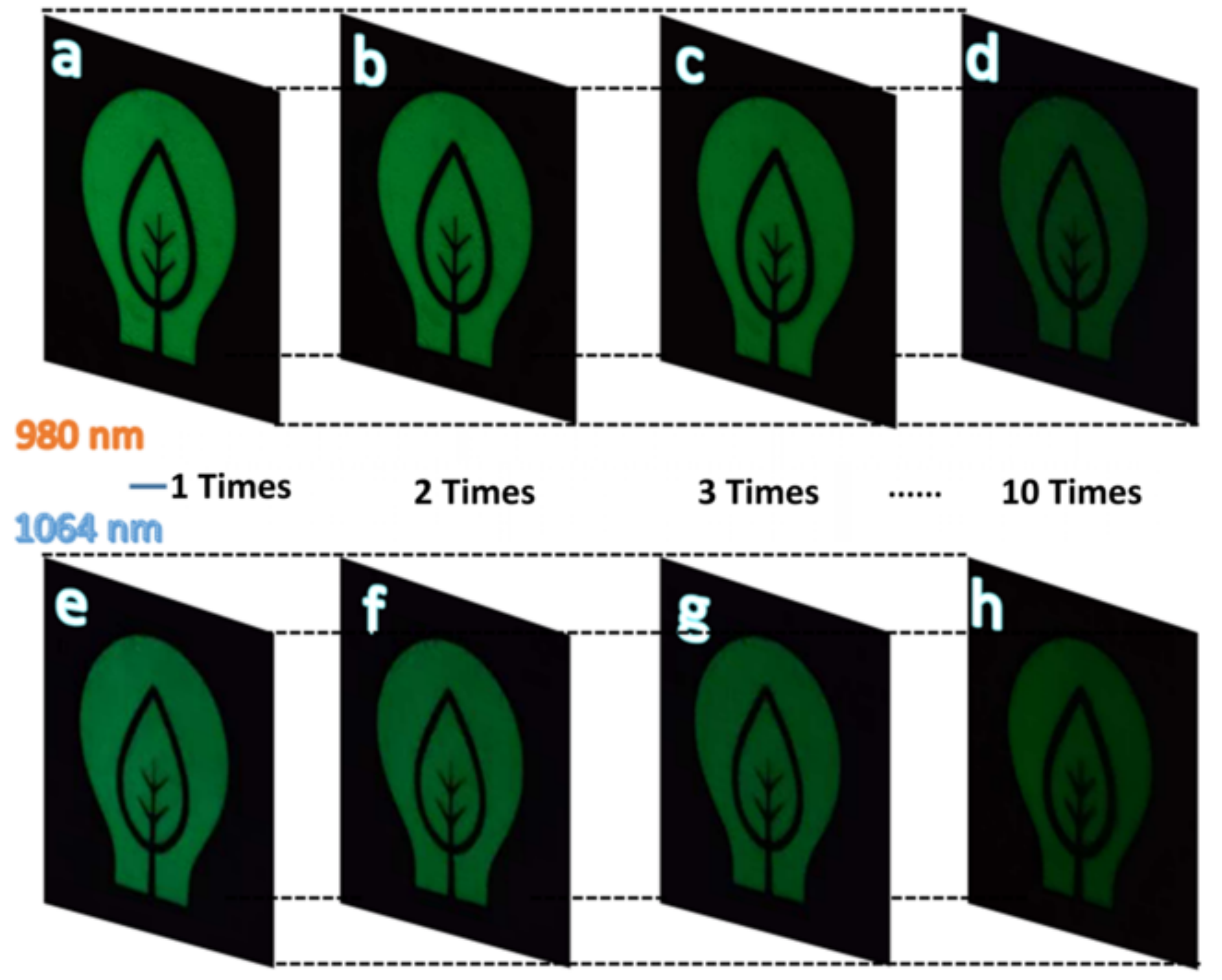




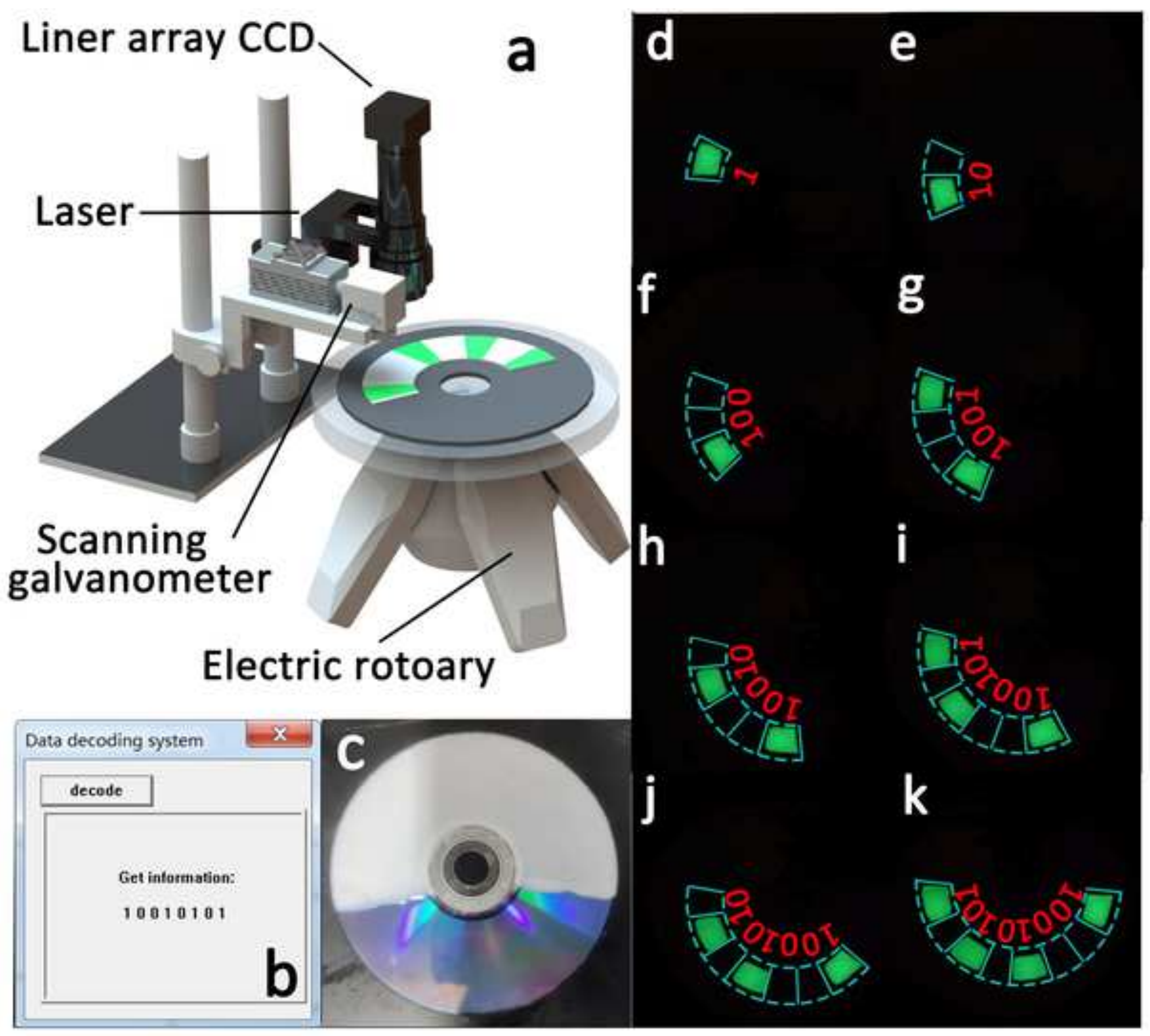



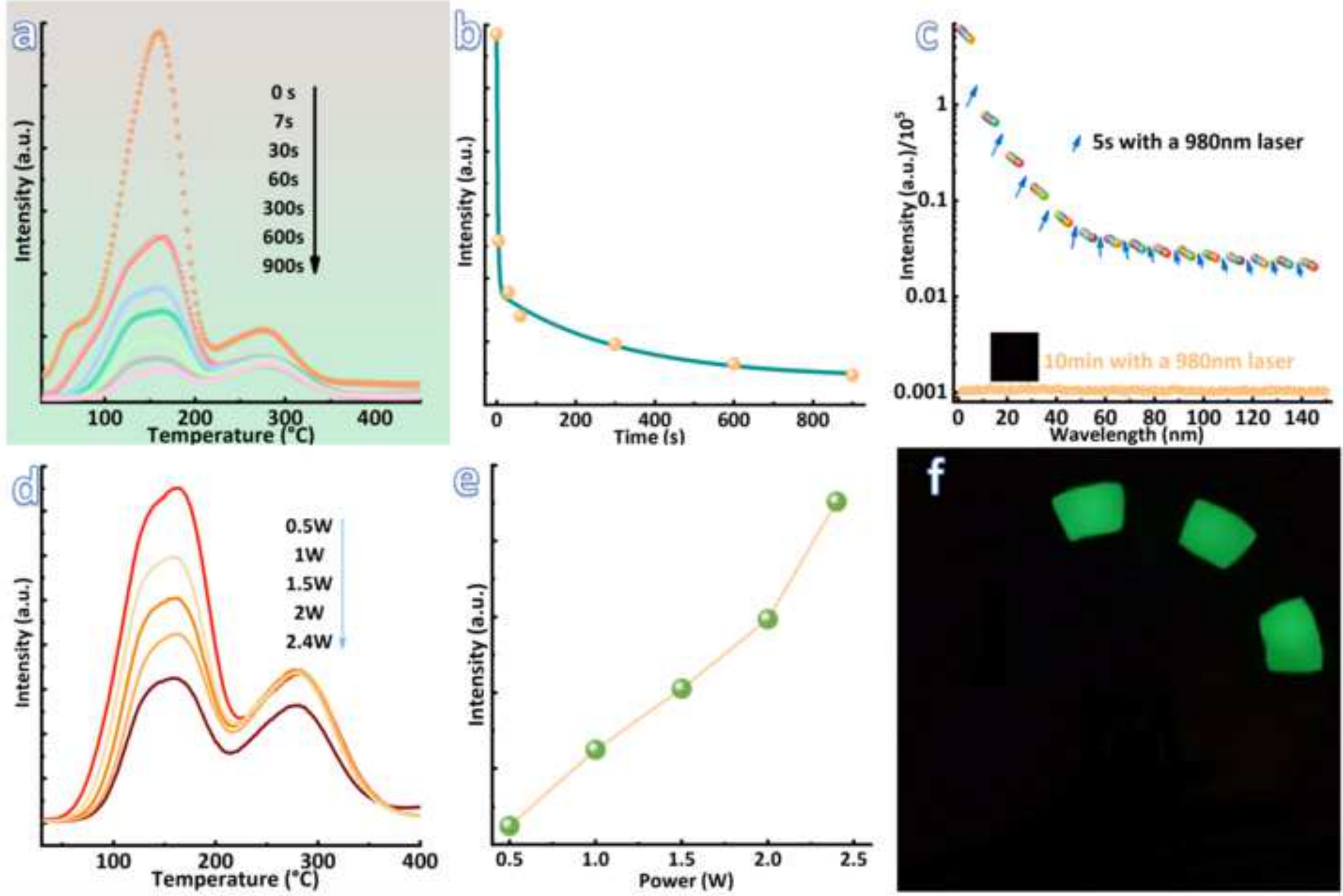